\title{
Ion Transport in the Colon of Rats Experimentally Infected with Liver Fluke (Fasciola hepatica)
}

\author{
Danuta Izabela KosIK-BOGACKA and Lidia KOŁODZIEJCZYK
}

Accepted September 6, 2004

\begin{abstract}
KosiK-BogACKA D. I., KoŁODZIEJCZYK L. 2004. Ion transport in colon of rats experimentally infected with liver fluke (Fasciola hepatica). Folia biol. (Kraków) 52: 243-246.

The effect of liver fluke infection (Fasciola hepatica) on ion transport in the rat proximal colon was evaluated with electrophysiological methods using an Ussing apparatus. Rats were orally infected with $F$. hepatica metacercariae. The experimental groups of rats at 4 weeks post-infection (wpi) were in the acute stage of fasciolosis, while those at 7,10 and 13 wpi represented the chronic phase of liver fluke infection. The control group comprised uninfected rats. The experiment consisted of recording transepithelial electrical potential difference (PD) and transepithelial electrical resistance (R) in the colon of the rats. The results revealed reduced PD levels in the colon of rats, especially during the acute phase of fasciolosis. During its chronic phase, a gradual growth in the intestinal transepithelial potential difference was found. Rat fasciolosis did not cause changes in colon sensitivity to mechanical stimulation or in the value of electrical resistance. Only at 13 wpi was resistance found to have dropped. The results have demonstrated that experimental fasciolosis leads to activation of inflammatory mediators and thus to stimulation of nerve fibres, which modifies ion transport in the epithelium of the host large intestine.
\end{abstract}

Key words: Fasciola hepatica, ion transport, Ussing apparatus.

Danuta KosiK-BoGaCKA, Lidia KoŁODZIEJCZYK, Chair and Department of Biology and Medical Parasitology, Pomeranian Medical University, Powstańców Wielkopolskich Av. 72, 70-111 Szczecin, Poland.

E-mail:kodan@sci.pam.szczecin.pl

E-mail:lkolo@sci.pam.szczecin.pl

The processes of ion transport in mammal intestine have been targeted in a number of studies focusing on either physiology or pathophysiology of the gastrointestinal tract (ARGENZIO et al. 1993; FIELD \& SEMRAD 1993; FRIELING et al. 1992; THORBOLL et al. 1998). In the epithelium of the colon, the processes of chloride ion secretion and sodium ion absorption run in parallel, however with differing intensity (KOSIK-BOGACKA et al. $2000,2002,2003)$. As a result of ion transport, electrical charges concentrate on both sides of the epithelium, which creates a measurable value, i.e. transepithelial electrical potential difference.

It is known that the presence of parasites in the host alimentary tract triggers a cascade of immunological responses. These result in intensive epithelial secretion of water and mucus as well as in contractions of the smooth muscles of gastric and intestinal walls (CIANCIO \& CHANG 1992). The problem of ion transport disturbances itself in parasitic infections has not been fully studied, and it presumably represents a significant aspect of their pathogenesis, which has been exemplified by relatively scarce reports on the effect of Cryptosporidium parvum (ARGENZIO et al. 1993) or $\mathrm{Hy}$ menolepis diminuta infections (PODESTA \& METTRICK 1977) on ion transport in the host alimentary tract.

The aim of the present study was to evaluate the effect of liver fluke (Fasciola hepatica) infection on ion currents in the epithelium of the proximal colon in rats. The experiments focused on both major stages of rat fasciolosis: (1) the acute phase related to juvenile flukes migrating to and growing in the liver parenchyma and (2) the chronic phase, during which the adult flukes occur in the bile duct.

\section{Material and Methods}

\section{Animals}

The experiment, after acceptance by Local Ethics Committtee (No 18/02, of $12^{\text {th }}$ March, 2002) was carried out on 28 male Wistar rats at an age of approx. 5 weeks. The rats received standard feed and water 
ad libitum throughout the experiment and were housed in a room illuminated for $12 \mathrm{~h}$ a day.

\section{Infection}

The metacercariae were collected from Lymnaea trunculata snails which had been infected with $F$. hepatica and cultured according to a modified method developed by TAYLOR and MOZLEY (1948) at the laboratory of the Department of Biology and Medical Parasitology, the Pomeranian Medical University in Szczecin. The rats were infected per os using a stomach tube with a dose of 30 metacercariae. The metacercariae were classified as viable if excretory granules were present, which was tested under an optical microscope (BORAY 1969). The rats were divided into five groups. Group I comprised uninfected rats (control group). Group II comprised rats at 4 weeks post-infection (4 wpi), which was a marker of acute phase of fasciolosis. Group III were rats at 7 wpi, which delimited the beginning of the chronic phase of infection. Groups IV and V comprised rats at, respectively, 10 and 13 wpi, i.e. at a period that corresponds to adult flukes being located in the common bile duct.

\section{Isolation and incubation of large intestine}

Control and infected rats were anaesthetized with ketamine and colons were immediately excised, washed with Ringer solution $\left(36^{\circ} \mathrm{C}\right)$ and trimmed of fat. The proximal colons were cut into suitable pieces and incubated in oxygenated Ringer solution of the following ionic composition (in mmol/l): $\mathrm{Na}^{+}(142.2) ; \mathrm{K}^{+}(4.0) ; \mathrm{Ca}^{2+}(4.4) ; \mathrm{Cl}^{-}$ (155.6); HEPES, N-[2-hydroxyethyl]-piperazine-N'-[2-ethanesulphonic acid] (10.0).

\section{Analytical equipment}

A classical version of the Ussing apparatus was applied in the experiment (KOEFOED-JOHNSEN \& USSING 1958), in which pieces of the intestine were placed between two chambers in vertical position (Fig. 1). The measurements of voltage and intensity of electric current were performed using four $\mathrm{Ag} / \mathrm{AgCl}$ electrodes. The $\mathrm{EVC} 4000$ voltage/current clamp apparatus (manufactured by WPI, USA) was applied in the laboratory as well as a BD 111 recorder (Kipp \& Zonen, The Netherlands) connected with the Ussing apparatus through $\mathrm{Ag} / \mathrm{AgCl}$ electrodes and agar bridges filled with $3 \% \mathrm{KCl}$ solution.

\section{Electrophysiological parameters measurements}

The experiments consisted of measuring transepithelial electrical potential difference (PD in $\mathrm{mV}$ ) and transepithelial electrical resistance ( $\mathrm{R}$ in $\left.\Omega \mathrm{xcm}^{2}\right)$ of an isolated intestinal wall. PD was determined when compensation current intensity of the external battery was $\mathrm{I}=0 \mathrm{~mA}$. R was determined with an electric impulse of $\mathrm{I}= \pm 10 \mathrm{~mA}$. Voltage changes were measured, and then $\mathrm{R}$ was calculated according to Ohm's law. Electrical stability of the measuring system was tested applying solutions on a synthetic cellophane membrane placed in the Ussing apparatus (blind sample). Mechanical stimulation (MS) consisted of splashing the large intestinal mucosa with a stream of Ringer solution from a distance of $12 \mathrm{~mm}$. A syringe was used for this purpose with a bent intravenous needle of 1.2 $\mathrm{mm}$ internal diameter. As a standard, an injection of $5 \mathrm{ml}$ of fluid during $10 \mathrm{~s}$ was applied.

\section{Statistical analysis of results}

Statistical hypotheses were tested using $\chi^{2}$ test for qualitative data evaluation, and using Student's $t$-test for quantitative data. The value of $\mathrm{P}<0.05$ was adopted as the significance level. The analyses were performed using "Statistica" software package on a 386 SX PC.

\section{Results}

The electrophysiological characteristics of isolated large intestines of control rats (group I) are presented in Table 1. The value of transepithelial electrical potential difference (PD) was $-1.5 \pm 0.3$ $\mathrm{mV}$, while resistance was $207.2 \pm 7.1 \Omega \mathrm{x} \mathrm{cm}^{2}$. Mechanical stimulation resulted in a temporary increase in $\mathrm{PD}$, i.e. hyperpolarization, which is presented in Figure 2a. PD growth began immediately with the stimulation. The highest magnitude of hyperpolarization occurred at the moment when stimulation finished. As soon as the stimulus activ-

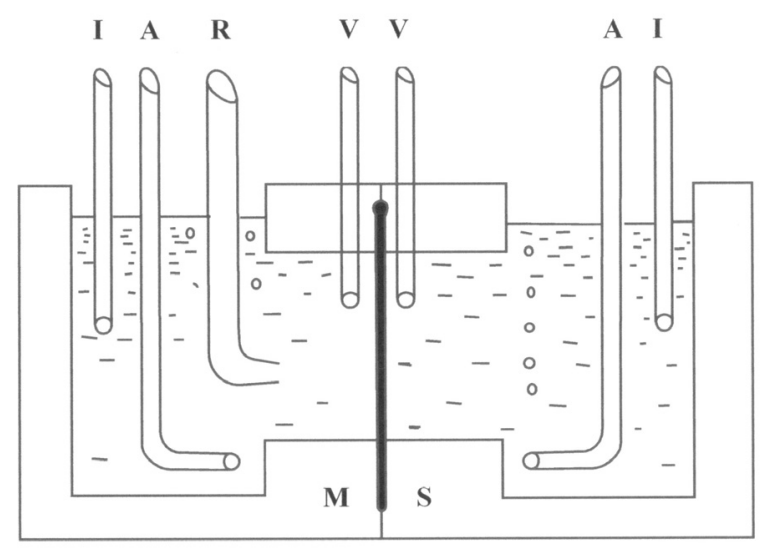

$\mathbf{T}$

Fig. 1. The Ussing chamber for measurements of transepithelial electrophysiological parameters of isolated large intestine (T). V, I - electrodes, A - air bubbling, R - jet flux from syringe (mechanical stimulation), $\mathrm{M}-$ mucosal, $\mathrm{S}$ - antiluminal side on the preparation. 
Table 1

Basic electrophysiological parameters of large intestine incubated in Ringer solution of control and Fasciola hepatica infected rats

\begin{tabular}{||l|c|c|c||}
\hline $\begin{array}{l}\text { Experimental } \\
\text { group }\end{array}$ & $\mathrm{PD}(\mathrm{mV})$ & $\mathrm{R}\left(\Omega \mathrm{xcm}^{2}\right)$ & $\mathrm{dPD}(\mathrm{mV})$ \\
\hline \hline $\begin{array}{l}\text { Group I (control) } \\
\mathrm{n}=9\end{array}$ & $-1.5 \pm 0.3$ & $207.2 \pm 7.1$ & $-0.7 \pm 0.1$ \\
\hline $\begin{array}{l}\text { Group II (4 wpi) } \\
\mathrm{n}=4\end{array}$ & $-0.1 \pm 0.1^{*}$ & $224 \pm 0.0$ & $-0.5 \pm 0.2$ \\
\hline $\begin{array}{l}\text { Group III (7 wpi) } \\
\mathrm{n}=4\end{array}$ & $-0.1 \pm 0.1 *$ & $190.5 \pm 5.0$ & $-1.1 \pm 0.4$ \\
\hline $\begin{array}{l}\text { Group IV (10 wpi) } \\
\mathrm{n}=4\end{array}$ & $-0.3 \pm 0.1 *$ & $189.5 \pm 11.5$ & $-0.6 \pm 0.3$ \\
\hline $\begin{array}{l}\text { Group V (13 wpi) } \\
\mathrm{n}=7\end{array}$ & $-0.6 \pm 0.2 *$ & $162 \pm 8.2 *$ & $-0.4 \pm 0.1$ \\
\hline
\end{tabular}

The mean SEM given. PD denotes the value of transepithelial electrical potential difference before mechanical stimulation, $\mathrm{dPD}$ denotes difference between the value during mechanical stimulation and the control $\mathrm{PD}$ value, $\mathrm{R}$ - value of electrical resistance in rat large intestine, $\mathrm{n}$ - number of colon preparations, * - significantly different from control group $(\mathrm{P}<0.05)$.

ity ceased, the PD value returned to the initial level. Numerical data depicting the effect of experimental fasciolosis on the studied electrophysiological parameters of the isolated rat intestine is presented in the further part of Table 1. At 4 weeks post-infection with $F$. hepatica (group II), the PD level of the intestine decreased by approx. 93\% as compared with the control. The hyperpolarization response resulting from mechanical stimulation was similar to that occurring in the control group (Fig. 2b), and so was the value of electrical resistance. In group III ( 7 wpi), the levels of the studied parameters did not show statistically significant differences compared with group II. In group IV (10 wpi), a three-fold increase of PD was found, as compared with groups II and III. The value of electrical resistance and mechanical stimulation response did not reveal any differences as compared with the control.

At 13 weeks post infection with $F$. hepatica (group V), PD increased twice as much as in the control group. The value of electrical resistance decreased by about $20 \%$, whereas sensitivity to mechanical stimuli did not change.

\section{Discussion}

In the uninfected rats (control), transepithelial electrical potential difference (PD) of the large in-

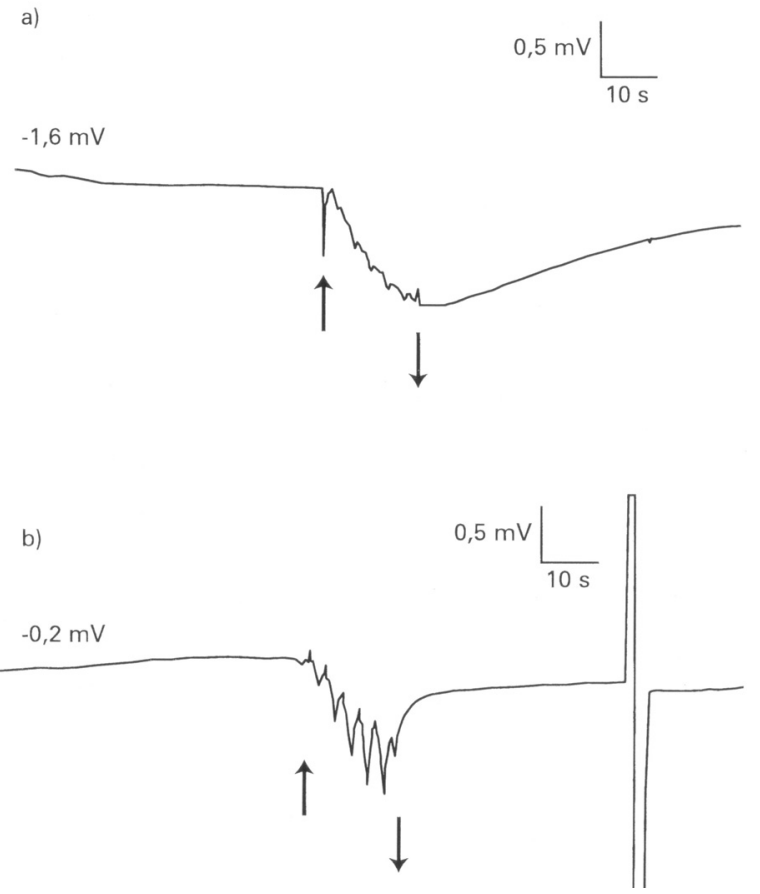

Fig. 2. The hyperpolarization of isolated large intestine (dPD) after mechanical stimulation: a - control rat, b infected rat (4 wpi). Stimulation was $10 \mathrm{~s}$ of jet rising. The start and finish of stimulation are denoted by the pair of arrows. Single experiments are shown.

testine during mechanical stimulation underwent short-term reversible changes in the form of hyperpolarization (Table 1, Fig. 2a). This may demonstrate the role of C-fibre endings in the response to mechanical stimulation. During the stimulation, sensory terminals release nonadrenergic and noncholinergic neurotransmitters (NANC), which stimulate ion transport in epithelial cells (BEVAN \& GEPPETTI 1994). A similar type of response to mechanical stimulation was previously described in isolated caecum of rabbit (KOSIK-BOGACKA et al. 2000, 2002, 2003). Mechanosensitivity of the large intestine did not reveal significant changes during fasciolosis, as the values of responses to mechanical stimulation of the infected and control rats were similar (Table 1). Mechanical damage to host liver as a result of migrating juvenile $F$. hepatica in the liver lead to typical pathomorphological changes, such as necrosis, fibrosis, cirrhosis, as well as inflammation of bile ducts in its chronic phase (DAWES 1963; Dow et al. 1967; KOŁODZIEJCZYK 1994; RUSHTON \& MURRAY 1977; THORPE 1965; URQUHART 1956). It has been known that inflammatory reaction leads to the secretion of neuropeptides of the NANC system from C-fibre endings, whose role consists of preserving tissue integrity and repairing damage done to tissue (COOKE 1994; FRIELING et al. 1992; SENGUPTA \& GEBHART 1994; THORBOLL et al. 1998). Then, local congestion appears, accompanied by increased permeability of epithelial blood vessels and the release of inflammatory mediators. As a consequence, muscle contractions occur and mucus se- 
cretion and ion transport intensifies (FIELD \& SEMRAD 1993; GRUBB 1999; MAGGI 1991). In the rats infected with $F$. hepatica, $\mathrm{C}$-fibres were not irritated, even in the phase of acute fasciolosis, or the amount of secreted neurotransmitters was very small and, consequently, did not stimulate ion transport.

In the infected rats, contrary to $\mathrm{dPD}$, a significant decline in the PD value of the large intestine was found, especially during acute fasciolosis (4 wpi, Table 1). This fact evidently demonstrates that liver fluke infections contribute to ion transport inhibition in the colon epithelium of the host. This is probably related to activation of inflammatory mediators in the host as a consequence of parasitic infection. On the other hand, in the chronic phase of fasciolosis (beginning 7 wpi), a gradual decrease of the colon transepithelial electrical potential difference was recorded. Presumably, this is related to intensification of repair processes in the host liver during this period of infection (MAFFEI FACINO et al. 1989; THORPE 1965) and, thus, to a reduced secretion of inflammatory mediators. On the whole, during experimental fasciolosis, the value of electrical resistance $(\mathrm{R})$ did not change either. Due to the fact that electrical resistance depends on the permeability of tight junctions, it can be concluded that the presented PD changes during mechanical stimulation of isolated rat colon resulted from changes in electrogenic ion transport, with a constant level of passive ion currents in the extracellular fluid. R level decreased at $13 \mathrm{wpi}$ only, which may have resulted from increased permeability of the tight junctions and, probably, was related to intensified inflammatory processes in the bile duct. Diarrhoeas observed in infected rats represented a confirmation of an increased permeability of tight junctions.

The conclusion is that during rat fasciolosis, ionic currents in the epithelium of the colon become inhibited with preserved tight junction continuity and sustained sensitivity to mechanical stimulation.

\section{References}

ArgenZio R. A., LECCE J., POWELl D. W. 1993. Prostanoids inhibit intestinal $\mathrm{NaCl}$ absorption in experimental porcine cryptosporidiosis. Gastroenterology 104: 440-447.

BeVAN S., GePpetTI P. 1994. Protons: small stimulants of capsaicin-sensitive sensory nerves. Trends Neurosci. 17: 509-512.
BORAY J. C. 1969. Experimental fascioliasis in Australia. Adv. Parasitol. 7: 95-210.

CiAncio M. J., ChANG E. B. 1992. Epithelial secretory response of inflammation. Ann. N. Y. Acad. Sci. 664:210-221.

COOKE H. J. 1994. Neuroimmune signaling of regulation in intestinal ion transport. Amer. J. Physiol. 226: G167-G178.

DAWES B. 1963. Hyperplasia on thebile duct fascioliasis and its relation to the problem nutrition in the liver fluke, Fasciola hepatica. Parasitology 53: 123-144.

Dow C., Ross J. G., TODD J. R. 1967. The pathology of experimental fascioliasis in calves. J. Comp. Pathol. 77: 377-385.

FIELD M., SEMRAD C. E. 1993. Toxigenic diarrheas, congenital diarrheas, and cystic fibrosis: disorders of intestinal ion transport. Ann. Rev. Physiol. 55: 631-655.

FRIELING T., WOOD J. D., COOKE H. J. 1992. Submucosal reflex: distension-evoked ion transport in the guinea pig distal colon. Amer. J. Physiol. 263: G91-G96.

GRUBB B. R. 1999. Ion transport across the normal and CF neonatal murine intestine. Amer. J. Physiol. 277: G167-G174.

KoEFOED-JOHNSEN V., USSING H. H. 1958. The nature of the frog skin potential. Acta Physiol. Scand. 42: 289-308.

KOŁODZIEJCZYK L. 1994. Study on glycogen content in the liver of mouse vs. pathomorphological changes in experimental fasciolosis. Acta Parasitol. 39: 211-216.

KOSIK-BOGaCKA D., BANACH B., TYRAKOWSKI T., BILICKA B. 2000. Pharmacological modification of ionic currents in epithelia by sensory neuropeptides. Med. Sci. Monit. 6: 887-891.

KOSIK-BOGACKA D., BANACH B., TYRAKOWSKI T. 2002. Effect of capsaicin on ion transport in caecum of rabbits. Pol. J. Pharmacol. 54: 475-482.

KOSIK-BOGACKA D., BANACH B., TYRAKOWSKI T., KOZŁOWSKA A., K̈OZŁOWSKA S. 2003. Effect of amiloride and bumetanide on ion transport in the caecum of rabbit. Pol. J. Pharmacol. 55: 213-219.

MAFFEI FACINO R., CARINI M., GENCHI C., TOFANETTI O., CASCIARRI I. 1989. Participation of lipid peroxidation in the loss of hepatic drug-metabolizing activities in experimental fascioliasis in the rat. Pharmacol. Res. 21: 549-560.

MAGGI C. A. 1991. Capsaicin and primary afferent neurons: from basic science to human therapy? J. Auton. Nerv. Syst. 33: $1-14$.

Podesta R. B., MetTerick D. F. 1977. Proximal-distal absorptive gradients in the in vivo intestine of normal and infected (Hymenolepis diminuta: Cestoda) rats. Can. J. Physiol. Pharmacol. 55: 791-803.

RUSHTON B., MURRAY M. 1977. Hepatic pathology of a primary experimental infection of Fasciola hepatica in sheep. J. Comp. Pathol. 87: 459-470.

SENGUPTA J. N., GEBHART G. F. 1994. Gastrointestinal afferent fibers and sensation. (In: Physiology of the Gastrointestinal Tract. Johnson L. R. ed., Raven Press, New York): 483-519.

TAYlor E. L., MOZLEY A. 1948. A culture method for Lymnaea truncatula. Nature 161: 894.

THORBOLl J. E., BINDSLEV N., TINDHOLDT T. T., SCHMIDT P., CHRISTENSEN P., SKADHAUGE E. 1998. Tachykinins mediate changes in ion transport in porcine jejunum through release of prostoglandins and neurotransmitters. Regul. Pept. 77: 105-111.

THORPE E. L. 1965. The pathology of experimental fascioliasis in the albino rat. J. Comp. Pathol. 75: 39-44.

URQUHART G. M. 1956. The pathology of experimental fascioliasis in the rabbit. J. Pathol. Bacteriol. 71: 301-310. 